\title{
Educação a distância: possibilidades e desafios para a aprendizagem cooperativa em ambientes virtuais de aprendizagem
}

\section{Distance education: challenges and possibilities for cooperative learning in virtual learning environments}

\author{
Suely Scherer ${ }^{1}$ \\ Glaucia da Silva Brito ${ }^{2}$
}

\begin{abstract}
RESUMO
Este artigo é resultado de um estudo que teve por objetivo analisar possibilidades de aprendizagem cooperativa em ambientes virtuais de aprendizagem de disciplinas e cursos oferecidos na modalidade de Educação a Distância $(\mathrm{EaD})$. O estudo foi realizado a partir da análise de registros em fóruns virtuais de disciplinas e cursos, apresentados em uma tese de doutorado e duas dissertações de mestrado. A análise dos dados foi orientada pelas pesquisas sobre aprendizagem cooperativa de Jean Piaget. O que se concluiu é que a vivência da aprendizagem cooperativa em ambientes virtuais depende de alguns fatores, dentre eles, a atitude de habitante do professor e do aluno. $\mathrm{O}$ habitante é aquele que aprende ao propor, questionar, se responsabilizando pelo ambiente, por sua aprendizagem e pela do grupo, ao realizar coordenações mentais externas e internas para a apreensão do objeto em estudo.
\end{abstract}

Palavras-chave: aprendizagem; comunicação; ambientes virtuais.

\begin{abstract}
This article is the result of a study that aimed to analyze the possibilities for cooperative learning in virtual learning environments for subjects and
\end{abstract}

DOI: $10.1590 / 0104-4060.38644$

1 Universidade Federal de Mato Grosso do Sul, Programa de Pós-Graduação em Educação (PPGE/UFMS). Campo Grande, Mato Grosso do Sul, Brasil. Cidade Universitária, s/n. CEP: 79070-900.

2 Universidade Federal do Paraná, Departamento de Comunicação Social. Curitiba, Paraná, Brasil. Rua Bom Jesus, 610. CEP: 80035-010. 
trainings offered through the Distance Education (DE) method. The study was conducted by analyzing records in virtual forums of subjects and trainings, presented in a doctoral thesis and two dissertations. Data analysis was guided by research on Jean Piaget cooperative learning. What was found is that the experience of cooperative learning in virtual environments depends on several factors, among them, the teacher and student inhabitant attitude. The inhabitant is the one who learns by proposing, questioning, taking responsibility for the environment, for his learning and the group learning, by performing external and internal mental coordination for the object apprehension under study.

Keywords: learning; communication; virtual environments.

\section{Introdução}

Embora professores e alunos envolvidos em ações na modalidade EaD estejam separados fisicamente, eles se tornam próximos quando há tecnologias digitais da informação e comunicação que possibilitam o encontro, a interação entre eles. Essa é a ideia básica da EaD, conforme sinalizam Moore e Kearsley:

A ideia básica de educação a distância é muito simples: alunos e professores estão em locais diferentes durante todo ou grande parte do tempo em que aprendem e ensinam. Estudando em locais distintos, eles dependem de algum tipo de tecnologia para transmitir informação e lhes proporcionar um meio para interagir (MOORE; KEARSLEY, 2007, p. 1).

No entanto, não basta disponibilizar "um meio" para que as interações aconteçam. A interação entre sujeitos não acontece apenas quando um entra em contato com o outro, quando um informa o outro de/sobre algo. Interação, segundo Piaget (1975), é uma ação de reciprocidade, que pode modificar as certezas dos sujeitos envolvidos no processo de aprendizagem. Portanto, as tecnologias digitais de comunicação e informação são "meios" para viabilizar interações, que por implicarem em mudanças nas certezas dos sujeitos envolvidos no processo, dependem da atitude desses frente às propostas de ações nos ambientes virtuais de aprendizagem.

Nesse contexto, no estudo que apresento neste artigo são discutidos possibilidades e desafios, a partir de interações entre sujeitos, de vivenciar proces- 
sos de aprendizagem cooperativa em ambientes virtuais de aprendizagem. O objetivo é analisar possibilidades de aprendizagem cooperativa em ambientes virtuais de aprendizagem de disciplinas e cursos oferecidos na modalidade de Educação a Distância (EaD).

O estudo foi realizado a partir de dados apresentados em uma tese de doutorado (SCHERER, 2005) e duas dissertações de mestrado (OLIVEIRA, 2012; FERNANDES, 2014). Os dados são recortes de registros de fóruns virtuais de disciplinas e cursos oferecidos a distância. A análise dos dados foi orientada pelos estudos sobre cooperação e aprendizagem de Jean Piaget.

\section{A atitude de habitante em ambientes virtuais de aprendizagem}

Os ambientes virtuais de aprendizagem são um lócus para a constituição de comunidades virtuais de aprendizagem.

Uma comunidade virtual é construída sobre as afinidades de interesses, de conhecimentos, sobre projetos mútuos, em um processo de cooperação ou de troca, tudo isso independentemente das proximidades geográficas e das filiações institucionais (LÉVY, 2000, p. 127).

Em cursos e ações na modalidade de Educação a Distância, a possibilidade de criarmos comunidades é importante no sentido de estabelecer-se uma relação de aprendizagem cooperativa entre os participantes. Uma comunidade virtual, devido à estética e recursos tecnológicos de que dispõe, pode contribuir para a formação de um sujeito mais cooperativo, pois em um ambiente virtual de aprendizagem, dificilmente estamos ou queremos estar sozinhos. É um espaço propício para a vida em comunidade, para o processo de comunicação de muitos para muitos, sem fronteiras, sem isolamentos; um espaço democrático, onde todos podem participar igualmente dos debates, das produções, das atividades. Mas, "longe de fundir as inteligências individuais em uma espécie de magma indistinto, a inteligência coletiva é um processo de crescimento, de diferenciação e de retomada recíproca das singularidades" (LÉVY, 1999, p. 32).

Ao participar de uma comunidade virtual, se vive junto e não sozinho, tendo sempre a possibilidade de recorrer a alguém, independentemente do tempo, para pedir informações ou para recebê-las, para comunicar, para informar, para 
se divertir, para refletir, para aprender. É preciso, entretanto, habitar, ser parte da comunidade, pois quem habita é responsável pelo ambiente e pelo grupo, participa, é leitor atento, questiona, propõe, cria coletivamente e individualmente, de forma responsável e comprometida, isto é, aprende.

Assim, caracterizo a atitude de alunos e professores ${ }^{3}$ em ambientes de aprendizagem virtuais em: habitantes, visitantes e transeuntes (SCHERER, 2005). Os habitantes são aqueles que se responsabilizam pelas suas ações e pelas dos colegas de ambiente virtual, buscando o entendimento mútuo, a ação comunicativa, o questionamento reconstrutivo; o habitante está sempre sendo parte (sentido dinâmico) do ambiente. Portanto, o encontramos sempre no ambiente, pois ele também vive lá, observando, falando, silenciando, postando mensagens, refletindo, questionando, produzindo, sugerindo, contribuindo com a história do ambiente, do grupo e dele.

Os visitantes são aqueles alunos e professores que participam do ambiente de aprendizagem com a intenção de visitar. Quando visitamos um ambiente, o fazemos impelidos por algum dever, por afeto ou por amizade. A ação livre para participar nem sempre está presente, lembrando que a palavra visitar vem do latim visitare, iterativo de videre, ver. Os visitantes participaram apenas para observar o que estava acontecendo, sem se co-responsabilizar com o ambiente, com o outro, ou com a produção coletiva. Alguns deles chegam a colaborar, mas sem chegar a cooperar com o grupo, pois são parte (sentido estático, momentâneo), algumas vezes, do ambiente, não estão sendo parte do ambiente continuamente, eles não habitam o lugar, o conteúdo, pois são visitantes.

Além de habitantes e visitantes, há os transeuntes. Os transeuntes dos ambientes de aprendizagem são aqueles alunos e professores que passam pelo ambiente. Alguns entram, circulando pelos espaços, outros apenas passam. Eles são passantes, nem visitantes, e nem habitantes. A origem da palavra transeunte vem do latim transire, passar além, passar de um lugar para outro, sem parar, é alguém de passagem. Os transeuntes passam pelo ambiente em um ou mais momentos, às vezes param para observar, mas sem se deter em nenhum espaço em especial, sem se responsabilizar, sem apreender para si o ambiente, sem colaborar ou cooperar. Se notada a presença deles, eles se relacionam alheios ao grupo e ao ambiente, pois são apenas passantes, nem visitantes e nem habitantes do lugar. São parecidos com os "zapeadores", aqueles que praticam o zapping com a televisão, internet, trocando de espaços, sem uma intenção em específico, sem saber para onde ir.

3 Neste artigo considera-se que o profissional que assume o papel de docente em um curso ou ação a distância é professor. 
Os habitantes, alunos e professores, são aqueles que constituem uma comunidade de aprendizagem. Uma pessoa só começa a fazer parte de uma comunidade, habitar um ambiente virtual, se ela sentir necessidade, se ela não encontrar em outro lugar o que a comunidade oferece. Nesse sentido,

[...] os educadores devem saber que o modo como o meio eletrônico é utilizado depende em grande parte das necessidades humanas, isto é, tanto dos professores quanto dos alunos, e que essas necessidades são a razão primeira por que se formam as comunidades educacionais eletrônicas (PALLOF; PRATT, 2002, p. 47).

Portanto, o professor habitante cria necessidades, motivos que torna importante, e que mobiliza a participação dos alunos em um ambiente virtual de aprendizagem. Um motivo é a maneira de questionar, de mobilizar o grupo, sem dar muitas respostas, deixando o caminho aberto ao diálogo, às ações que favorecem a aprendizagem cooperativa em ambientes virtuais.

\section{Aprendizagem cooperativa}

A aprendizagem cooperativa em ambiente virtual de aprendizagem é discutida neste artigo a partir dos estudos de Jean Piaget. Segundo esse pesquisador, o sujeito, aluno ou professor, age e aprende quando se sente desafiado, quando sente alguma necessidade, quando está interessado ou intrigado com algo, quando está disposto, ou seja, quando há algum desequilíbrio cognitivo momentâneo entre o meio que o cerca e o seu organismo. Piaget afirma ainda que a afetividade é o aspecto energético que mobiliza o sujeito para a ação, e que está sempre relacionada a um conteúdo, no entanto, o sujeito precisa de estruturas prévias capazes de dar conta desse conteúdo. Nesse sentido, segundo Becker:

Afirmar que o sujeito tem interesse por um objeto é o mesmo que afirmar que o sujeito reclama, efetivamente, a assimilação deste objeto. Do mesmo modo, afirmar que o sujeito tem necessidade é o mesmo que afirmar que ele possui esquemas que exigem sua utilização. Quanto maior for a necessidade tanto maior será o grau de assimilação e de acomodação 
virtuais e tanto maior será a relação entre os esquemas e uma situação determinada (BECKER, 1997, p. 55).

Os esquemas são as diversas formas pelas quais o sujeito realiza a ação assimiladora, ao apreender o que é novidade. Em função dessa novidade, o sujeito reconstrói os seus instrumentos de assimilação, redimensionado-os, pela ação chamada por Piaget de acomodação. Esse movimento ocorre sempre que o sujeito está em desequilíbrio cognitivo em relação a algum objeto do conhecimento e busca o equilíbrio, restabelecendo-o. Este restabelecimento acontece quando o sujeito acomoda a novidade que originou o desequilíbrio às estruturas mentais já existentes, considerando a existência de esquemas de assimilação. Essa novidade é uma resposta provisória à pergunta, à dúvida, que gerou o desequilíbrio, pois sempre poderão surgir novos desequilíbrios.

É nesse processo de busca pelo equilíbrio, ao compreender e apreender a novidade, acomodando o desconhecido ao que é conhecido, que o sujeito aprende. Ele coopera, opera mentalmente com e sobre as suas certezas, e com e sobre as certezas de outros e do meio, busca o equilíbrio, que é sempre provisório, pois deixa de existir ao surgir um novo desequilíbrio.

Piaget (1995) afirma que os desequilíbrios podem ter origem em várias situações: nos conflitos entre o sujeito e os diferentes objetos, pela insuficiência de acomodação e pela não confirmação das certezas prévias à interação com o objeto. Os desequilíbrios também podem ser causados por conflitos entre subsistemas do sujeito, por falta momentânea de coordenação ou ainda pelo desequilíbrio entre a diferenciação e a integração, permanecendo esta, de início, insuficiente.

$\mathrm{O}$ questionamento presente na fala do professor precisa desequilibrar o aluno em relação às suas certezas, sendo capaz de gerar novos conflitos cognitivos. Assim, para questionar de forma desafiadora, "desequilibrante", construindo no aluno a dúvida, é importante o professor deixar o aluno falar, "não esgotar nada, não desviar nada e, ao mesmo tempo, saber buscar algo preciso, ter em todo momento alguma hipótese de trabalho para comprovar" (CASTORINA et al., 1988, p. 60).

O questionamento precisa ser desafiador, desequilibrando cognitivamente o aluno ao ser questionado, deixando-o perplexo, em dúvida quanto às certezas que possui, ou à ação que pratica. A pergunta desafiadora oportuniza o pensar, o operar, e a tomada de consciência da provisoriedade das certezas e das dúvidas do sujeito questionado; ela favorece a aprendizagem do aluno. O movimento da pergunta, do questionamento, é favorecido pela atitude do professor: de 
abertura, de reciprocidade, de humildade, de envolvimento e comprometimento, de desafio, de responsabilidade.

Além do movimento da pergunta, presente na ação do professor, que pode gerar o movimento de cooperação interna e a cooperação externa entre dois sujeitos, é importante pensar em uma educação que favoreça o processo de cooperação externa entre mais sujeitos. Nesse sentido, ao pensar a educação em um processo cooperativo, nós temos de aprender a cooperar, satisfazendo as três condições propostas por Piaget (1977), que promovem a busca de um estado de equilíbrio na ação dialógica entre mais sujeitos: 1) as pessoas envolvidas no diálogo devem possuir uma escala comum de valores intelectuais (linguagem, sistemas de noções,...) para que se compreendam sobre o sentido das palavras que empregam e sobre a definição das noções que constituem estas significações; 2) ao afirmar algo, cada pessoa deve justificar o seu ponto de vista, sentindo-se obrigado a seguir a proposição que reconhecer como válida, não se contradizendo; 3) é necessária uma reciprocidade de pensamento entre os parceiros. Habermas (2003), ao falar do agir comunicativo, fala das mesmas condições para se chegar ao consenso, a um entendimento sobre um objeto em estudo, o que nos possibilita afirmar que, para que ocorra a cooperação, é necessário que os sujeitos estejam envolvidos em uma ação comunicativa.

É importante destacar, além das condições já propostas, que na ação de cooperação é necessário seduzir o outro ao invés de submetê-lo à nossa opinião. Além disso, nessa ação cada um aceita ou incorpora o outro domínio como parte sua, passando para esse sem negar a si mesmo. Assim, esse aceite é diferente de simplesmente tolerar o outro e sua ideia, pois tolerância é uma negação postergada, é considerar que o outro está equivocado.

Além da tolerância, Morin (2000) destaca outras ameaças ao processo de comunicação e de cooperação. Essas ameaças caracterizam o mal-entendido e o não entendido: a polissemia de uma noção; a ignorância dos ritos e costumes do outro; a incompreensão dos valores imperativos propagados no seio de outra cultura; a incompreensão dos imperativos éticos próprios a uma cultura, não compreendendo as ideias ou os argumentos de outra visão do mundo; a impossibilidade de compreensão de uma estrutura mental em relação à outra. Daí a importância de, em ações de Educação a Distância, planejarmos espaços e ações que possibilitem a socialização dos conhecimentos prévios de cada educando, as suas histórias, a aprendizagem de atitudes como o respeito e a abertura, promovendo um processo educacional em que os sujeitos aprendam ao conviver com o outro.

As condições para a cooperação apontadas por Piaget são válidas tanto para ações comunicativas entre professor e aluno, quanto para os processos de aprendizagem cooperativa em grupos maiores, pois a responsabilidade e 
envolvimento devem ser de todos os sujeitos que habitam o ambiente virtual de aprendizagem.

Portanto, a cooperação proporcionada pelo agir comunicativo só acontecerá se o grupo conseguir coordenar seus pontos de vista, usando palavras com sentido conhecido por todos ou definindo-as no campo comum ao grupo, apresentando argumentos para as suas proposições, e sendo responsáveis em relação aos seus parceiros de discussão. A cooperação deixa de acontecer se faltar reciprocidade entre os envolvidos, respeito mútuo, ou quando um dos envolvidos partir da ideia de que o seu ponto de vista é o único possível.

O professor que atenta a essas questões, tem elementos para articular os debates em ambientes virtuais. Ainda assim, deve atentar para não ter a falsa ideia de equilíbrio nas discussões do grupo, coagindo os alunos a "pensarem" como ele ou ela. Se isso acontecer, não há cooperação, pois não há operação conjunta, nem construção de consenso, apenas consentimento, que causa a falsa ideia de uma conclusão comum, um falso equilíbrio cognitivo.

A cooperação se opõe à opressão, a simples troca espontânea e ao egocentrismo, pois temos de estar abertos à troca, a discutir o nosso ponto de vista, e temos de nos descentrar, deixando de ser o centro das atenções e da comunicação.

A cooperação supõe a autonomia dos sujeitos envolvidos, ou seja, supõe a liberdade de pensamento, a liberdade moral e a liberdade política. Portanto, com a proposição livre de diferentes pontos de vista, é possível a cooperação, ou seja, uma coordenação de ações, a busca de um entendimento, um consenso em torno do objeto de estudo. Essa coordenação de ações é que provoca no sujeito a permuta do pensamento com os outros, pois sem ela dificilmente o sujeito conseguiria agrupar suas operações em um todo coerente.

O agrupamento é, pois, uma forma de equilíbrio das ações interindividuais, e encontra assim sua autonomia no seio, mesmo, da vida social. O agrupamento constitui, por princípio, uma coordenação dos pontos de vista, e isto significa, realmente, uma coordenação entre observadores, portanto uma cooperação de vários indivíduos (PIAGET, 1972, p. 210).

Ao cooperar e buscar a coordenação de ações em um grupo, segundo Piaget (1973), a troca de proposições constitui uma lógica, pois acarreta em um agrupamento geral devido às correspondências, às reciprocidades ou às complementaridades dos agrupamentos solidários. Esse movimento, em um grupo de alunos com um professor, em torno de um objeto de estudo, envolve alguns tipos de proposições: proposições iguais, quando uma corresponde à 
outra; proposições diferentes, que necessitam de um acordo entre os envolvidos na busca de uma afirmação comum, que justifique a diferença entre os pontos de vista; e ainda podemos ter proposições complementares. Em um ambiente de aprendizagem, as proposições contrárias são importantes para estimular, entre sujeitos, interrogações, insatisfações, dúvidas, reticências e busca.

Uma proposição é um ato de comunicação que constitui sempre uma operação efetuada por um sujeito, pois os intercâmbios do próprio pensamento obedecem também a uma lei de equilíbrio, a qual, constitui um agrupamento operatório, uma cooperação, mesmo que interna. Portanto, teremos sempre cooperações internas e externas.

A coordenação de ações externa provoca uma coordenação interna, que é o processo de coordenar os conceitos em nossas próprias redes de conhecimento. Ela é feita pelo sujeito que participa do processo de aprendizagem, seja aluno ou professor, e a coordenação externa é feita por todos os sujeitos que interagem, ao mesmo tempo, podendo ser orientada ou desafiada pelo professor. Portanto, não é somente o educador que faz as coordenações externas para o aluno, ele apenas desafia para que o educando as faça, senão teremos a falsa cooperação e, talvez a falsa aprendizagem.

As coordenações internas só podem ser feitas pelo próprio sujeito, o professor não fará pelo aluno, e o aluno não poderá fazer pelo professor, e um educando não poderá fazer por seu colega; cada sujeito necessita de esquemas mentais para fazer a coordenação interna. Daí a importância de o professor apreender os conhecimentos prévios do aluno, pois esses sinalizam os esquemas que o mesmo possui.

E por falar em cooperação, temos ainda de distingui-la da colaboração, mesmo que ambas sejam ações relevantes em uma proposta de Educação a Distância, por promoverem a aprendizagem. A cooperação é diferente da colaboração, pois colaborar é operar isoladamente sobre um objeto em estudo, sem criar algo com o outro, sem buscar um entendimento comum; colaborar é operar paralelamente à operação mental do outro. E cooperar é operar em comum, isto é, “ajustar por meio de novas operações (qualitativas ou métricas) de correspondência, reciprocidade ou complementaridade, as operações executadas por cada um dos parceiros" (PIAGET, 1973, p. 105).

Nessa perspectiva, é possível afirmar que a colaboração é uma operação "solitária" na ação, não envolve operações para ações de reciprocidade, complementaridade ou correspondência com a de outros. O que temos muito presente em vários espaços virtuais é apenas a colaboração. Para cooperar, temos de habitar os espaços, temos de agir e operar mentalmente com o outro. A aprendizagem cooperativa exige a capacidade de pensar, participar e conviver coletivamente, responsabilizando-se com o grupo, e buscando na reciprocidade 
não um fim predeterminado, mas um entendimento, um consenso produzido na ação comunicativa.

Assim, ao cooperar, habitamos o ambiente virtual em que estamos participando, na busca do consenso. Essa participação é a ação de modificar e interferir na proposição do outro, ao propor. Para ser habitante de ambiente virtual, o professor e alunos precisam "ler" as proposições e questionamentos dos outros e expor a sua opinião e questões, contribuindo para movimentos de busca de coordenações externas com os demais habitantes do espaço, não se limitando a coordenações internas, ou a ser apenas "leitor".

Um dos desafios nas ações de Educação a Distância $(\mathrm{EaD})$ é que professores e alunos sejam habitantes de espaços virtuais, favorecendo processos de aprendizagem cooperativa, ao vivenciarem coordenações externas e internas. E com foco nesse desafio, serão analisados a seguir dados de três pesquisas que envolveram ações de $\mathrm{EaD}$ em ambientes virtuais de aprendizagem.

\section{Aprendizagem cooperativa em fóruns virtuais: possibilidades e desafios}

Os desafios para que a cooperação seja vivenciada em ambientes virtuais de aprendizagem são muitos, e a maioria das ações na modalidade $\mathrm{EaD}$ que observamos ainda evidenciam uma prática de interação que se limita a ações de pergunta e resposta entre professor e aluno, chegando no máximo em ações de colaboração. Assim, para discutirmos algumas possibilidades e desafios de aprendizagem cooperativa em ambientes virtuais de aprendizagem, neste artigo, foram selecionados dados de fóruns analisados em três pesquisas.

Uma das pesquisas é a minha pesquisa de doutorado (SCHERER, 2005), que teve por objetivo apresentar e analisar uma estética para a Educação Bimodal, identificando atitudes, espaços e ações de educadores e educandos que favoreçam aprendizagens e comunicações em ambientes presencias e virtuais, coerente com a estética da complexidade. As outras duas pesquisas são de mestrado, orientadas por mim: a pesquisa de Oliveira (2012), cujo objetivo foi analisar possibilidades de aprendizagem em uma ação de formação continuada de professores de matemática, na modalidade $\mathrm{EaD}$, em ambientes virtuais de aprendizagem; e a pesquisa de Fernandes (2014), que teve por objetivo analisar o uso de tecnologias digitais em cursos de Licenciatura de Matemática, na modalidade $\mathrm{EaD}$, oferecidos por instituições do sistema Universidade Aberta do Brasil (UAB). 
Na pesquisa de Scherer (2005) foram explicitados e analisados vários diálogos retirados de fóruns virtuais da disciplina de Estatística Aplicada à Educação, lócus da pesquisa. A disciplina foi ofertada em um processo de Educação Bimodal (parte presencial e parte a distância, em um total de 17 encontros, sendo seis a distância), para 38 alunas de um curso de Pedagogia, sendo ministrada pela autora deste artigo.

O movimento de cooperação em um grupo maior de pessoas pode ser gerado em vários momentos no ambiente virtual, e nesse caso, o movimento da pergunta e da ação comunicativa é provocado tanto pelo professor quanto pelo aluno. Para discutir possibilidades de aprendizagem cooperativa com os dados dessa primeira pesquisa, destaco um debate iniciado no oitavo encontro da disciplina (quarto encontro a distância), no ambiente virtual, quando se discutia o arredondamento de dados numéricos. A cooperação se desencadeou a partir de uma pergunta elaborada por uma das alunas, conforme o recorte de um fórum que segue (foram usadas as mensagens originais das alunas e iniciais dos seus nomes para identificá-las nos fóruns):

Meninas como fica o arredondamento do valor 6,252? (apenas uma casa decimal) estou esperando as respostas. V.A.

Oi pessoal. Sobre arredondamento, o que sei é que quando o $2^{\circ} n^{\circ}$ após a vírgula for maior que 6, o $n^{\circ}$ depois da virgula aumenta; se for menos continua o mesmo. Acho que é isso. Se estou errada me corrijam. Bom, vou tentar responder a questão da V. A. COMO o valor que ela nos dá é 6,252, e como já falei antes, se o valor for maior que 6 aumenta, se for menor continua o mesmo valor que já existia após a vírgula, então a resposta é 6,2. E. D.

Veja meu raciocínio se está correto: quando eu tenho um número, por ex.: 2,13, e eu desejo arredondar este valor eu posso deixar pelo valor 2. Me lembro que os professores faziam este trabalho e explicavam o seguinte: se o $n^{\circ}$ for 2,75 , eu posso arredondar para 3, pois é um valor mais aproximado de 3; se for 2,13, eu poderei arredondar para 2. Tem alguma lógica esta ideia? Se tiver então eu poderei responder que o resultado da pergunta da V.A. é de 6. Peço ajuda, pois eu não sei se expliquei ou se compliquei ainda mais. A. P.

[...] o número que a V.A. nos coloca se encaixa na regra especifica do 5 , que diz: quando o primeiro $n^{\circ}$ a ser abandonado for 5 e o que vier atrás for diferente de zero, aumenta-se também um $n^{\circ}$ naquele que vem após 
a vírgula, sendo que assim 6,252 fica 6,3. Entretanto, no livro (p. 49), nos exemplos que tem sobre esta mesma regra de 5 , não entendi por que 76,250002 fica 76,3, pois segundo o que entendi depois do 5 não poderia vir o $n^{\circ} 0$ para aumentar 1. Gostaria de entender o por quê disso, será que alguém poderia me ajudar? Abraços... M. I.

Surgiram, inicialmente, três proposições diferentes, e observa-se que as alunas buscavam o entendimento comum em um movimento de cooperação. Ainda sem a professora realizar intervenções, esperavam para que outras alunas se pronunciassem ou que uma das alunas envolvidas na discussão aparecesse registrando outra proposição em relação à questão. E foram surgindo outras proposições que podemos observar no recorte que segue:

Oi. M. I., infelizmente não vou poder te ajudar porque também vou precisar de ajuda neste item. Na verdade estou confusa com relação à pg. 49, onde diz que se ao 5 seguir em qualquer casa um algarismo diferente de 0, aumenta-se uma unidade ao algarismo a permanecer. Mas com os exemplos eu me confundi: 2,352=2,4, aqui eu entendi, mas 25,6501=25,7 eu achava que não aumentaria, pois após o 5 temos um zero. Aí eu pergunto, só não aumenta se todos os algarismos após o 5 forem zero? F. E.

Respondendo a dúvida da M. I., eu acredito que é porque "se ao 5 seguir e QUALQUER casa um algarismo DIFERENTE de zero, aumenta-se uma unidade ao algarismo a permanecer", do livro. Como temos um 2 no final, não podemos anulá-lo, então aumentamos para reduzir a uma casa decimal. F. E., concordo quando comenta: "que só não aumenta quando Todos os algarismo após forem zero". Foi isso que entendi ao ler o livro e de cuidar muito ao precisar de notas para ser aprovada na escola. S. B.

A aluna S. B. apareceu com uma proposição de correspondência à de M. I., fortalecendo a busca por um entendimento comum no grupo. E a discussão, para F. E., gerou outros desequilíbrios internos, fazendo com que ela lançasse para o grupo uma pergunta suscitada pelo seu movimento de apreender o objeto em estudo, no caso, os arredondamentos de dados numéricos.

Aos poucos, as alunas chegavam a um consenso como podemos observar no diálogo que segue: 
No caso do 25,6501. Primeiro verificamos se o que se quer é uma casa decimal.

O número depois do 6 é 5, ai verifica-se se tem outras casas decimais diferentes de zero. Se tiver, como é o caso, aumenta-se uma unidade da $1^{a}$ casa decimal, ficando 25,7.

Se fosse tudo zero, 25,6500, ficaria 25,6, pois quando o último algarismo é 5 e depois dele só seguirem zeros, só será aumentada uma unidade se o número da $1^{a}$ casa decimal for ímpar, no caso não é. Ex.: 25,75000 $=25,8$ (a primeira casa decimal é ímpar e depois do 5 só tem zeros); $25,65000=25,6$ (a primeira casa decimal é par, então se conserva a $1^{a}$ casa decimal) ... T. H.

Bem, com relação ao exemplo que a $V$. A. apresentou eu acredito, como a M. I. também, que o arredondamento fica: 6,252=6,3, pois como consta no livro, a regra em relação ao cinco diz que após ele seguir um número diferente de zero aumenta-se uma unidade, uma casa decimal. Quanto aos outros exemplos estou tentando compreender! Beleza!! C. L.

Quando a certeza começou a se estabelecer no grupo, como professora percebi que era o momento de entrar na discussão; resgatei diferentes proposições, me posicionando e orientando quanto ao que as alunas estavam discutindo, e abrindo o diálogo para novas questões...

Oi, meninas...

[...]

Muitas questões foram lançadas e discutidas e posso concluir que muitas conseguem fazer a ligação com a leitura feita. A M. I. e a S. B. justificaram bem a questão do arredondamento do 6,252 para 6,3. Se tiverem dúvidas voltem à mensagem delas. Quanto ao 76,250002, fica 76,3 , pois o valor 5 será abandonado (ao se arredondar para uma casa decimal), e tendo qualquer número diferente de zero (no caso é 0002), após o 5, arredonda-se para mais, ou seja, para 76,3.

[...]

Observem que não se arredonda pelo abandono da unidade após a vírgula, só se formos arredondar para um número inteiro. O valor a ser abandonado é que interessa. Por exemplo, se quero arredondar o valor 3,65879 (para uma casa decimal fica 3,7; para duas casas decimais fica 3,66; para três casas decimais fica 3,659...). Quem se habilita a justificar cada caso? Suely. 
O que se percebe é que as condições para o processo de cooperação sugeridas por Piaget foram surgindo timidamente nos diálogos: a inteligibilidade nas palavras, a proposição de certezas e a busca do entendimento se evidenciam durante o diálogo estabelecido nesse fórum. E há um movimento de descentração, de deixar de ser o centro, deixando de considerar a sua a ideia principal e única, na busca pela compreensão do ponto de vista do outro, na abertura para o diálogo dos habitantes do ambiente.

Para focar-me na ação de uma aluna ao vivenciar a aprendizagem cooperativa, usarei registros de uma aluna identificada por A. P., retirados da pesquisa de Scherer (2005). O movimento de aprendizagem iniciou-se quando a aluna A. P. se desequilibrou em relação ao conceito de porcentagem, após o seu contato com proposições de colegas e da professora em um dos fóruns da disciplina:

20/03 - Esta conta que A. D. fez me deixou mais confusa ainda. E pergunto: Por que não podemos fazer contas de porcentagem utilizando regra de três? Na estatística o cálculo deve ser diferente? Eu tenho muitas dúvidas porque eu não entedia porcentagem utilizando regra de três, $e$ agora piorou, se possivel alguma contribuição sobre porcentagem, pois sei de sua importância, porém não compreendo como utilizá-la em sala de aula. Me dá um nó na cabeça só de pensar. Suely, transmiti de maneira prazerosa mas eu não consigo transferi-la para a prática. Alguém me dê uma luz, para clarear minhas dúvidas que são muitas... A. P.

O momento do desequilíbrio cognitivo estava evidente. Assim, a busca pelo equilíbrio seria iniciada. O restabelecimento do equilíbrio só acontece quando o sujeito acomoda o que é novo, e o que originou o desequilíbrio, às estruturas mentais já existentes, conforme referencial teórico adotado. O novo é uma resposta provisória à pergunta que gerou o desequilíbrio, e depende das estruturas de assimilação do sujeito. Nesse sentido, o meu papel de professora na pesquisa foi o de acompanhar os movimentos da aluna, questionando de forma a dar elementos para que ela continuasse buscando, oferecendo novas informações, e criando possibilidades para que a aluna criasse novas estruturas de assimilação.

A importância do papel do professor nesse processo aparece no primeiro momento de equilíbrio da aluna, ainda provisório, mas já fazendo uma proposição mais confiante, embora equivocada, em relação ao conceito de porcentagem. E o desequilíbrio na busca de equilíbrio foi um movimento contínuo como podemos observar em seu registro: 
22/03 - Professora Suely, agora compreendo por que nos questionava sobre regra de três. O problema não é usá-la, mas por que usá-la. Penso que a regra de três é uma forma mais simples e que pode avançar para novos estágios. Nosso grupo discutiu a porcentagem de maneira diferente, o que me deixou interessada em descobrir outras coisas sobre estatística e como aplicá-la em uma turma de crianças. Agora, tentando responder a questão da professora, vamos analisar por partes. Eu A. P. comprei uma calça de $R \$ 38,50$ e ganhei $8 \%$ de desconto. Qual foi o valor da calça? Bem, se 38,50 representa 100\% do meu valor e eu quero descobrir 8\% deste, como irei chegar ao valor final? Eu dividiria 100 por 8, que daria 12,5, e dividindo 38,50 por 12,5 o valor de desconto seria de $R \$ 3,08$. A. P.

A aluna continuou buscando o equilíbrio em interações com outras colegas, com a professora, e aos poucos apreendeu a novidade, acomodando o desconhecido ao que era conhecido. Ela cooperou, operando mentalmente com e sobre as suas certezas, e com e sobre as certezas de outros e do meio, buscando o equilíbrio. Depois de várias interações no ambiente virtual, leituras, e a compreensão do conceito de porcentagem em um patamar superior, com reflexões, a aluna alcançou um equilíbrio:

03/04 - Sobre porcentagem penso que estou bem, mas existe um ditado que diz o seguinte: "Quando achamos que sabemos todas as respostas vem o tempo e muda nossas perguntas". É assim que estou me sentindo. Já consigo compreender que ao resolver um já conta, do tipo calcular $12,5 \%$ de um total de 400 crianças. Primeiramente irei calcular 400 por 100, para pegarmos, se é que a turma me entende, 0 valor de $1 \%$ de 400 alunos. Pra depois multiplicar por 12,5\%. A resolução do problema ficaria assim: $400: 100=4$ e 12,5x4=50.

Ou seja, 12,5\% representa 50 crianças. Até este momento tudo que escrevi já foi comentado. Mas lendo algumas contribuições percebi que o ramo de discussão é sobre $10 \%$. Bem, o que eu posso entender em $10 \%$, se $1 \%$ representa 1 em cada $100,10 \%$, seria 10 em cada 100.10 em cada 100 é o mesmo que 1 em cada 10. Não é difícil de compreender. A conta sobre $10 \%$ em 300. Primeiro descobrir 1\%, 300:100=3. Depois $10 \times 3=30$, dando a ideia de um décimo, uma fração, sendo o mesmo que meio um terço, um quarto... Que se refere à contribuição da E. D. sobre fração... A. P. 
Como professora desse grupo de alunas, o meu papel foi de oferecer condições para que ela (A. P.) encontrasse o equilíbrio cognitivo, não dando resposta, mas alimentando a sua dúvida, criando situações que contribuíssem com a sua aprendizagem a partir dos conhecimentos que já possuía. Assim, busquei apreender a sua forma de compreender. No espaço virtual pude cuidar dela isoladamente, questionando-a, acompanhando os seus movimentos nos fóruns e nos espaços de produção individual. Tarefa difícil, que exige tempo, muito mais que a carga horária da disciplina, mas uma tarefa necessária se nos importamos com a aprendizagem dos alunos.

A aluna vivenciou uma aprendizagem cooperativa porque estava aberta a aprender, habitando os espaços, estabelecendo uma relação ao mesmo tempo fechada e aberta. Aberta, em sua relação com o meio e com os outros, e fechada, ao buscar e estruturar internamente a compreensão dos diferentes movimentos que aconteceram, na busca de um novo equilíbrio. E é importante que o professor conheça este processo, pois o sujeito aprendiz deve ser provocado/desafiado/ seduzido para compreender as ligações, as articulações, as implicações, as imbricações, as interdependências e as complexidades, que fazem parte dele e das organizações em sua volta.

O que se percebe nos fóruns, nesta busca pelo entendimento mútuo, são movimentos de cooperação interna e coletiva, com ações comunicativas que são ao mesmo tempo complementares, concorrentes e antagônicas, contribuindo para a aprendizagem de cada um dos sujeitos que habita o ambiente virtual. O desafio que desencadeia a cooperação tem origem em questões e posicionamentos dos alunos e, às vezes, do professor. Nos dois casos, entretanto, é necessário que ambos sejam habitantes, que não apenas visitem ou passem por ele.

Para analisar mais diálogos em ambientes virtuais, passamos para os dados de uma segunda pesquisa. Na pesquisa de Oliveira (2012), ao considerar a importância de habitar ambientes virtuais em ações desenvolvidas na modalidade de EaD, discutiu-se possibilidades de aprendizagem de conceitos matemáticos por professores ao participarem de um curso de formação continuada a distância. O curso tinha carga horária de 30 horas, e foi desenvolvido durante três meses. Iniciaram o curso 40 professores e 26 o finalizaram. O professor formador foi o autor da pesquisa.

Inicialmente apresento o recorte de um processo de interação ocorrido no $1^{\mathrm{o}}$ encontro da ação de formação cujo objetivo foi o de refletir sobre conceitos da função do $1^{\circ}$ grau a partir de uma situação-problema. O professor formador iniciou o diálogo com questionamentos, na tentativa de desencadear desequilíbrios cognitivos nos alunos, no caso, os professores cursistas que participavam da ação de formação. 


\section{1/09/2011 - Olá pessoal,}

Vamos começar nossas discussões sobre a álgebra e o uso de computadores. Como desafio inicial, a partir da situação proposta na agenda, reflitam e vamos debater as seguintes questões, sempre justificando a resposta: A situação dada representa uma função? Qual a relação matemática que representa esta função? Qual o domínio desta função?

Antes de participar do nosso fórum, leia o que já discutimos e envie a sua mensagem, dando continuidade ao estudo.

Vamos interagindo.... Abraços. FORMADOR

Os cursistas começaram a postar suas proposições, conforme podemos observar a seguir, no recorte de fórum retirado da pesquisa de Oliveira:

12/09/2011 - Sim, esta situação representa uma função pois existe uma "dependência" entre o custo e a quantidade de latas, ou seja, para uma determinada quantidade de latas existe um determinado custo, e para que seja calculado o custo de " $n$ " latas, usamos a sentença matemática $y=1,5 x . N N$.

13/09/2011 - A Situação apresentada representa uma função, sendo função linear $f(x)=a x$, onde $b=o$, neste caso $f i c a f(x)=1,5 x$, o valor total a ser pago depende da quantidade de refrigerante que for comprado, $o$ domínio neste caso é o x e será maior que zero. $L C V$.

13/09/2011 - Olá Pessoal! Concordo com os colegas, a referida situação representa uma função do $1^{\circ} \mathrm{grau}$, sendo representada por: $f(x)=1,5 x \mathrm{com}$ domínio $x>=0$, sendo que $f(x)$ depende dos valores que são atribuídos para $x$. No caso da questão em discussão, $f(x)$ dependerá da quantidade de latinhas de refrigerantes consumidas. Abraços! LAG.

13/09/2011 - Sim, esta situação representa uma função $y=1,50 . x$, sendo o domínio desta função, a variável x pode assumir qualquer valor real. Sendo $x=>0$. ZTL.

13/09/2011 - Olá pessoal! Sim, a situação dada representa uma função. $f(x)=x .1,5=>$ Através desta função $f(x)$ quantidade de refrigerantes comprados em reais e $x$ é a quantidade de refrigerantes que serão consumidos. $X=>0$ não podendo ser negativo. Domínio desta função $D$ $=\{x E N\}$ Abraços. RCSFJ.

13/09/2011 - A situação dada representa uma função $f(x)=x$. 1,5 Através desta função $f(x)$ quantidade de refrigerantes comprados em reais e $x e ́$ a quantidade de refrigerantes que serão consumidos. Logo $X=>0$ não podendo ser negativo. Domínio da Função = Números Naturais. MAPSR. 
13/9/2011 - [...] O NN, o LCV, a LAG e a ZTL afirmam que a situação, sendo função, pode ser representada pela sentença matemática y $=1,5 x$. $O$ RCSFJ e a MAPSR afirmam que a sentença deve ser $y=x .1,5$. Então questiono para o grupo: essas sentenças são iguais ou diferentes? Por quê? Qual delas representa melhor a situação dada? Por quê? Vamos dialogar... FORMADOR (OLIVEIRA, 2012, p. 26).

O que se observa é que alguns cursistas (a maioria) parecem observar as proposições dos colegas, mas não as citam, não buscam cooperar, não se co-responsabilizam com a aprendizagem dos colegas, e muitas vezes apenas repetem o que o colega postou, sem afirmarem que são proposições iguais, diferentes ou complementares. O objetivo dos cursistas parece ser o de responder a questão encaminhada pelo professor formador, exceto no caso do cursista LAG. Ele explicita um desejo em cooperar com o grupo ao mencionar que concorda com as proposições dos colegas, apresentando proposições iguais aos dos dois colegas que enviaram proposições anteriormente.

No entanto, o cursista LCV complementa informações apresentadas por $\mathrm{NN}$, falando em domínio da função, por exemplo, mas nada cita em relação ao que o colega afirmou, como se estivesse agindo de forma isolada sobre o objeto em estudo, evidenciando uma ação que podemos chamar de colaboração com o professor formador ou simplesmente um movimento de resposta ao professor. RCSFJ apresenta uma forma diferente de representar a função, mas nada comenta sobre as proposições anteriores, novamente caracterizando uma ação isolada sobre o objeto em estudo. É importante discutir qual o objetivo em ações isoladas como essa. Para que responder a pergunta do professor e não discuti-la? No entanto, esses são os diálogos que mais encontramos em ambientes virtuais nos cursos oferecidos na modalidade EaD. Daí a importância do papel do professor. Podemos observar que esse faz uma intervenção no sentido de desafiar os cursistas para uma aprendizagem cooperativa.

Na sequência das postagens desse fórum, os cursistas ainda apresentaram proposições isoladas, e o formador continuou fazendo articulações e solicitando que o grupo se articulasse com as questões que pontuava. Assim, em Oliveira, após intervenções do professor formador, o movimento se alterou, conforme podemos observar:

14/9/2011 - Concordo com o registro de MMRM, apenas mudou a variável para q, que não altera a função tradicionalmente colocada como: $f(x)=1,5 x$. O registro de MMRM não deixa de ser uma função 
$f(v) q^{*} 1,5$, uma vez que o valor a ser pago vai depender sempre da quantidade q(refrigerante). $L C V$.

14/9/2011 - [...] O domínio desta função linear em $N$ e a Imagem em $N$. $f(V)=Q . P \quad$ onde $V=$ Valor a ser pago, $Q=$ quantidade de latinhas $e$ $P=$ preço da unidade

Mas também estive pensando nesta questão, se aplicasse esta atividade para os alunos, eles usariam $N^{*}$ (excluindo o zero), pois a indicação é que a compra se inicia com uma lata de refrigerante. Abraços. MMRM. 15/9/2011 - Concordo com suas palavras MMRM, os alunos irão se prender aos dados do problema. MEFL.

14/9/2011 - Sendo assim, temos uma função.

$x=$ parte literal

1,5 = coeficiente numérico

Sabemos que a ordem dos fatores não altera o produto para essa função apresentada: $f(x)=x .1,5$ ou $f(x)=1,5 . x .[\ldots]$

Sobre o L.C.V. concordar que os registros: $f(x)=1,5 x$ e $f(v)=q^{*} 1,5$, são iguais. Qual o sentido matemático existente nestes registros? Eu não concordo, pois $v$ e q são valores diferentes. Logo, mudando todo um contexto de raciocínio. Concordaria se ele me mostrasse que $v=q * 1,5$ seria $y=1,5 . x$ ou $f(x)=y=1,5 . x$. RCSFJ.

15/9/2011 - Olá RCSFJ, Concordo com suas afirmações. Você, de forma muito clara, conseguiu esmiuçar todos os questionamentos apresentados pelos demais colegas. MSC (OLIVEIRA, 2012, p. 63-64).

As proposições que os cursistas começaram a apresentar evidenciam um processo de cooperação em que encontramos proposições iguais, diferentes e complementares. Os cursistas buscam se articular com as proposições dos demais, na busca de um entendimento sobre o objeto do conhecimento em estudo: LCV apresenta uma proposição igual à de MMRM, justificando seu posicionamento; MEFL evidencia uma proposição correspondente à de MMRM; e RCSFJ apresenta uma proposição contrária à de LCV, que pode estimular novas interrogações e busca do entendimento comum em torno do objeto, que se inicia por MSC ao mencionar que concorda com a proposição do colega. No entanto, MMRM apresenta uma proposição que parece ainda isolada, nada mencionando sobre proposições correspondentes postadas anteriormente.

A análise desses pequenos recortes de diálogos no fórum tem o objetivo de explicitar possibilidades de aprendizagem cooperativa em ambientes virtuais. Nessa pesquisa destaca-se o desafio na ação do professor formador, que precisa habitar o ambiente virtual, desafiando os cursistas para a aprendizagem cooperativa. Ele assumiu um papel nem sempre fácil, e segundo Oliveira, ele: 
[...] deve estar atento a "tudo" e a "todos", analisando as certezas apresentadas pelos professores em formação; analisando o processo de aprendizagem destes e trazendo questões que mantenham os professores na busca pelo conhecimento. [...] O professor formador precisa estar presente virtualmente, sendo habitante do ambiente virtual (OLIVEIRA, 2012, p. 81-82).

A necessidade de o professor ser habitante do ambiente virtual e conhecer o seu papel no processo de aprendizagem do aluno fica evidente também na pesquisa realizada por Fernandes (2014). O autor analisa em sua pesquisa dois cursos de Licenciatura em Matemática, ofertados na modalidade EaD, a partir de duas categorias, sendo uma delas a categoria de "Interação entre Sujeitos". Nessa categoria, ele analisou como alunos e professores interagiram ao usar o Ambiente Virtual de Aprendizagem (AVA) no desenvolvimento de aulas, destacando o modelo de interação proposto no curso. Observaram-se os AVA das disciplinas oferecidas nos dois cursos durante o ano de 2012.

Fernandes explicita um início de diálogo entre duas alunas ( $\mathrm{Z}$ e $\mathrm{S})$ no AVA da disciplina de Cálculo II de um dos cursos investigados, e menciona que o fórum finalizou-se com as duas postagens:

Aluna Z: Oi meninas! Tô precisando de uma luz...

Tava terminando esta questão e já estou com 5120pi^4 e mais outras coisas... Acho que devo ter um erro nas potências.

Antes de integrar, usando a fórmula, eu tenho raiz(4t^2+10t^4).Vocês encontraram isso também?

Fiz a integral por $u^{\wedge} n d u$, tomando $u=\left(4 t^{\wedge} 2+10 t^{\wedge} 4\right)$ e $n=0,5$, fiz $d u=d t$ mas não sei se está certo,

Abraços

PS: Usando o software Derive deu raiz(160pi^2+4)^3/15 - 4/15

Aluna S: Olá aluna Z!

Sabe a fórmula da integral que vc chegou, tb cheguei à mesma coisa.

Fiz assim: Põe o t`2 em evidência e tira para fora da raiz, vc terá t(raiz $\left.4+10 t^{\wedge} 2\right)$

$u=4+10 t^{\wedge} 2$

$d u=20 t d t$, $d t=d u / 20 t$.

Aí a integral fica t (raiz u) du/20t, corta os te fica (raiz u)du, resolve por u^n. e aplica os limites na seguinte: 1/20(2/3 (raiz4 +10t²)`3)

Espero que tenha ajudado,

Mas minha resposta deu diferente

$a b c ̧$

(FERNANDES, 2014, p. 107-108). 
Pode-se inferir que a aluna $\mathrm{Z}$ tinha o interesse de estabelecer um espaço de cooperação com os demais colegas, mas, recebeu retorno apenas da Aluna $S$, mas ela também não retornou para o fórum para a continuidade do diálogo. Esse recorte de diálogo evidencia uma possibilidade de o grupo vivenciar a aprendizagem cooperativa, no entanto, um desafio que se explicita é a necessidade da presença do professor como habitante desse espaço. Questões como: onde estava o professor durante este diálogo? Que intervenção poderia ter realizado no fórum e em outros espaços chamando os alunos para habitarem o fórum? A cooperação em ambientes virtuais só é possível se os habitarmos, e, um primeiro passo é o professor ser habitante, ter conhecimento das implicações de seu papel no processo de aprendizagem dos alunos.

Para discutir um pouco mais a importância do papel do professor, resgata-se em Fernandes um recorte do Fórum da "Questão 4" da disciplina de Cálculo III do segundo curso investigado, no qual foram registradas 110 postagens:

Aluna R: Tutor $D$, a equação no plano tangente nos pontos $(0,1, f(0,1))$ está em anexo. vc acha q. está correto?

Tutor D: dá uma conferida na tua derivada parcial em relação a y. No ponto pedido. $q$ dependendo vai mudar to plano que vc achou.

Aluna R: Tutor D, a minha resolução da 4.b. tbem ficou diferente, mas o resultado éo mesmo da colega Aluna C. Em anexo eu coloquei o resultado das parciais, vc poderia dar uma analisada e ver se estou fazendo alguma coisa errada?

Tutor D: Estão certas as derivadas parciais.

Aluna C: As derivadas parciais da $4 b$ estão iguais... a diferença é que vc simplificou (FERNANDES, 2014, p. 80-81).

Uma primeira certeza que surge desse recorte é que a quantidade de postagens não implicou em qualidade das interações ou em maior possibilidade de vivência de aprendizagem cooperativa pelo grupo de alunos e professor (que no contexto da pesquisa tinha a denominação de tutor). O que se observa é um diálogo um a um, entre o professor e cada um dos alunos; um espaço coletivo de aula, usado para atendimento individual apenas.

Mas, precisamos pensar em possibilidades de aprendizagem cooperativa nesse espaço. Essas surgem da proposta e papel do professor, que poderia convidar e desafiar os demais colegas a analisarem as questões propostas pelas alunas $\mathrm{R}$ e C. No entanto, ele se limitou a responder a questão das alunas, dirigindo-se isoladamente a cada uma delas. 
Mesmo o professor agindo de forma isolada, sem aproveitar a possibilidade de iniciar um processo de cooperação com o grande grupo, a aluna $\mathrm{R}$ observou a proposição da aluna $\mathrm{C}$, que observou a proposição da aluna $\mathrm{R}$, iniciando um movimento que podemos chamar de colaboração entre as duas, finalizando com a afirmação da aluna C. A ação evidencia uma colaboração, pois a aluna $\mathrm{C}$ se preocupou apenas em dar um retorno, não agindo sobre e com as proposições da aluna $\mathrm{R}$, na busca de uma coordenação das ações, de um entendimento mútuo. A aluna $\mathrm{R}$ também não agiu sobre a proposição da aluna $\mathrm{C}$, pois o diálogo sobre a questão finalizou-se como mostrado no recorte.

No fórum "Questão 7", da disciplina de Cálculo II, do mesmo curso, também observamos possibilidades de aprendizagem cooperativa, no entanto, o professor estava ausente. Vejamos um recorte do fórum apresentado em Fernandes:

Aluna Z: Oi Aluna H! Eu encontrei um valor diferente do seu. Pra mim a integral do item b) deu 8/35. Abraços.

Aluno C: letra a) $1 / 6$ letra b) $8 / 35$. Chegaram nisso?

Aluna H: Oi Aluno $C$, chegamos ao resultado 1/4. Como ve montou sua integral?

Aluno $\boldsymbol{C}$; montei de:

$$
\begin{aligned}
& 1<y<2 \\
& 2-y<x<\text { raiz de }\left(2 y-y^{\wedge} 2\right) \\
& \text { e vcs? }
\end{aligned}
$$

Aluno M: Meu resultado fechou assim tb. (FERNANDES, 2014, p. 83).

Os alunos $\mathrm{Z}, \mathrm{C}, \mathrm{H}$ e $\mathrm{M}$ dialogam sobre uma das questões propostas na disciplina. Observa-se que a aluna $\mathrm{Z}$ se limita a colaborar com a aluna $\mathrm{H}$, fornecendo uma resposta, sem o objetivo de agir sobre as certezas da aluna $\mathrm{H}$, não retornando ao fórum para discutir a questão, coordenar ações. $\mathrm{O}$ aluno $\mathrm{C}$ evidencia seu interesse por cooperar com os demais colegas, tanto em sua pergunta inicial (chegaram nisso?), quanto no momento em que explicita a forma como pensou, abrindo-se para dialogar sobre a sua proposição, na busca por coordenações internas e externas. A aluna $\mathrm{H}$ demonstra o mesmo interesse pela busca de um entendimento comum sobre a questão em estudo (Como vc montou sua integral?).

Esse diálogo traz uma possibilidade para o professor habitar o espaço, desafiando para um movimento contínuo de cooperação, apresentando novas questões, articulando, cooperando com os alunos. Mas, ele não se fez presente, o que nos possibilita inferir sobre a necessidade da formação dos professores, 
mais um desafio para criarmos verdadeiros espaços virtuais de aprendizagem cooperativa.

O que temos observado é que há muito por avançar em pesquisas na área de EaD que investiguem possibilidades e desafios da aprendizagem cooperativa em AVA. Estudos como o de Fernandes (2014, p. 125) sinalizam a importância dessas pesquisas, em virtude da ausência, em cursos ofertados na modalidade de $\mathrm{EaD}$, de "[...] processos de interação e produção coletiva no AVA que desafiem, mobilizem os alunos, tutores e professores para a construção de conhecimento".

\section{Considerações finais}

O estudo apresentado neste artigo aponta que muito ainda há por investigar e investir em ações que favoreçam a aprendizagem cooperativa em ambientes virtuais de aprendizagem, especialmente quando falamos em fóruns de disciplinas ou cursos oferecidos na modalidade de Educação a Distância. Muitas são as possibilidades de vivenciar a aprendizagem cooperativa, mas maiores são os desafios para que ela seja oportunizada.

O que se pode concluir é que há possibilidades de vivenciar processos de aprendizagem cooperativa em ambientes virtuais, mas, essas dependem da atitude de alunos e professores de assumirem-se habitantes do ambiente virtual, da disciplina, do curso. Para tal, nesse espaço coletivo, torna-se necessário que o aluno seja co-responsável pela aprendizagem do outro, do grupo, sentindo-se parte desse, se posicionando, apresentando proposições sejam elas correspondentes, antagônicas ou complementares às dos colegas e do professor, na busca pela coordenação de ações externas e internas, para a compreensão do objeto em estudo.

Assumir-se habitante de ambientes virtuais é um dos maiores desafios para professores e alunos vivenciarem processos de aprendizagem cooperativa. Aliada a esse desafio está a necessidade de o professor conhecer e dispor-se a aprender ao longo de sua profissão as características específicas do ensino e da aprendizagem na modalidade de $\mathrm{EaD}$, compreendendo-a como um espaço de educação. Daí surge a demanda pela formação continuada de professores para atuarem nessa modalidade. 


\section{REFERÊNCIAS}

BECKER, Fernando. Da ação à operação: o caminho da aprendizagem em J. Piaget e P. Freire. 2. ed. Rio de Janeiro: DP\&A, 1997.

CASTORINA, José Antônio et al. Psicologia genética: aspectos metodológicos e implicações pedagógicas. Tradução de José Cláudio de Almeida Abreu. Porto Alegre: Artes Médicas, 1988.

FERNANDES, Frederico Fonseca. O uso de tecnologias digitais na modalidade EaD: um estudo sobre cursos de formação inicial de professores de matemática. 139f. Dissertação (Mestrado em Educação Matemática) - Universidade Federal de Mato Grosso do Sul. Campo Grande, MS, 2014.

HABERMAS, Jürgen. Consciência moral e agir comunicativo. 2. ed. Tradução de Guido A. De Almeida. Rio de Janeiro: Tempo Brasileiro, 2003. 236p.

LÉVY, Pierre. A inteligência coletiva: por uma antropologia do ciberespaço. Tradução de Luiz Paulo Rouanet. 2. ed. São Paulo: Loyola, 1999. 212p.

LÉVY, Pierre. Cibercultura. Tradução de Carlos Irineu da Costa. 2. ed. São Paulo: Ed. 34, 2000. 264p.

MOORE, M. G.; KEARSLEY, G. Educação a Distância: uma visão integrada. Tradução de Roberto Galman. São Paulo: Thomson Learning, 2007.

MORIN, Edgar. Os sete saberes necessários à educação do futuro. 3. ed. Tradução de Catarina Eleonora F. da Silva e Jeanne Sawaya. São Paulo: Cortez; Brasília, DF: UNESCO, 2000.

OLIVEIRA, Agnaldo de. Formação continuada de professores de matemática a distância: estar junto virtual e habitar ambientes virtuais de aprendizagem. 88f. Dissertação (Mestrado em Educação Matemática) - Universidade Federal de Mato Grosso do Sul. Campo Grande, MS, 2012.

PALLOF, Rena M.; PRATT, Keith. Construindo comunidades de aprendizagem no ciberespaço: estratégias eficientes para salas de aula on-line. Tradução de Vinícios Figueira. Porto Alegre: Artmed, 2002.

PIAGET, Jean. Psicologia da inteligência. 2. ed. Tradução de Egléa de Alencar. Rio de Janeiro: Fundo de Cultura, 1972.

PIAGET, Jean. Estudos sociológicos. Tradução de Reginaldo Di Piero. Rio de Janeiro: Forense, 1973.

PIAGET, Jean. A Construção do Real na Criança. Rio de Janeiro: Zahar, 1975.

PIAGET, Jean. A tomada de consciência. Tradução de Edson Braga de Souza. São Paulo: Melhoramentos, 1977. 
PIAGET, Jean. Abstração reflexionante: relações lógico-aritméticas e ordem das relações espaciais. Tradução de Fernando Becker e Petronilha Beatriz Gonçalves da Silva. Porto Alegre: Artes Médicas, 1995.

SCHERER, Suely. Uma Estética Possivel para a Educação Bimodal: Aprendizagem e comunicação em ambientes presenciais e virtuais. 241f. Tese (Doutorado em Educação) - Pontifícia Universidade Católica de São Paulo, São Paulo, 2005.

Texto recebido em 21 de novembro de 2014. Texto aprovado em 05 de dezembro de 2014. 
